\title{
Investigations of residual stress distributions in retained austenite and martensite after carbonitriding of a low alloy steel
}

\author{
Richard J. Katemi ${ }^{1, a}{ }^{*}$, Jérémy Epp ${ }^{1, b}$, Franz Hoffmann ${ }^{1, c}$, \\ Matthias Steinbacher ${ }^{1, d}$ \\ ${ }^{1}$ Stiftung Institut für Werkstofftechnik, Badgasteiner str. 3, 28359 Bremen, Germany \\ arkatemi@udsm.ac.tz ${ }^{\text {b }}$ epp@iwt-bremen.de ${ }^{c}$ hoffmann@iwt-bremen.de,
}

Keywords: Carbonitriding, residual stress, retained austenite, martensite.

\begin{abstract}
Specimens of low alloy steel were carbonitrided under different conditions to attain varying levels of carbon and nitrogen contents. The residual stress depth distribution was evaluated in martensite and retained austenite by X-ray diffraction. Beside standard evaluations, triaxial residual stress states with $\sigma_{33} \neq 0$ in both phases were also considered. High values of residual stresses in both phases were observed. The sign, magnitude and location of maximum compressive residual stresses were greatly influenced by the level of carbon and nitrogen contents.
\end{abstract}

\section{Introduction}

The carbonitriding process is the modified form of carburizing [1] during which ammonia gas is added into the carburizing atmosphere. The main advantage of this process in comparison to carburizing is the rapid diffusion of carbon $(\mathrm{C})$ and nitrogen $(\mathrm{N})$ as well as the formation of high compressive residual stresses (RS) in the case. High compressive RS and hardness enhance the fatigue properties of components like shaft, gear and bearing and improves resistance to wear, bending fatigue, and rolling fatigue [2]. In recent years, several studies [3, 4] have focused on the investigation of carbonitriding process and the resulting residual stresses (RS) in the case. Even though to date, still nearly all published data on RS belong to martensite/bainite phase and only little information on retained austenite (RA) residual stress state in carbonitrided specimens is available. Nowadays, however, the trend is toward retaining high percentage of austenite in the case aiming at improved contact, bending and impact fatigue. It is evident that due to high amount of RA ( $>30$ Vol. \%), the sign, magnitude and distribution of RS in both martensite and RA phase will be influenced and such influences may affect the mentioned properties [5]. Therefore, the RS in martensite and in austenite have to be considered. Varying the level of $\mathrm{C}+\mathrm{N}$ content in solution affects not only the amount of RA but also the magnitude and distribution of RS. Therefore, a need arises for thorough understanding the effect of different level of $\mathrm{C}$ and $\mathrm{N}$ contents on the sign, magnitude and distribution of RS. Moreover, it is still unclear whether the residual stress state measured by laboratory XRD in a multiphase material is a plane stress state due to the low penetration depth, or if a triaxial residual stress state with $\sigma_{33} \neq 0$ of opposite signs is present in the phases that compensate each other to macroscopic $\sigma_{33}=0[6]$.

In the present work, carbonitrided specimens made of steel grade 18CrNiMo7-6 were investigated in terms of RS distribution in both martensite and RA phases according to the standard $\sin ^{2} \psi$ method. Beside standard evaluations, triaxial evaluations of residual stresses with $\sigma_{33} \neq 0$ in both phases were also considered by using different strategies. Further, chemical and phase compositions were investigated.

\section{Materials and methods}

The material investigated in this study was a steel grade $18 \mathrm{CrNiMo} 7-6$ with following chemical composition: Fe-0.157C-1.63Cr-1.57Ni-0.52Mn-0.26Mo-0.27Si-0.03S-0.02Al in Mass.- $\%$. Samples with a diameter of $34 \mathrm{~mm}$ and a thickness of $8 \mathrm{~mm}$ were prepared and then carbonitrided. The initial microstructure consists of ferrite + pearlite. Two carbonitriding experiments were carried out. In the first condition $(C N 1)$, the reached surface composition was $0.56 \mathrm{Mass} . \% \mathrm{C}$ and 
0.4 Mass. $-\% \mathrm{~N}$ and in the second condition (CN2), the surface composition was 0.87 Mass. $-\% \mathrm{C}$ and 0.34 Mass.- $\%$ N. After carbonitriding, specimens were quenched into oil held at $60{ }^{\circ} \mathrm{C}$.

Retained austenite analysis. The determination of the amount of RA was performed by a D8Diffractometer and a Vantec-1 Bruker-AXS position sensitive detector. For the measurements, $\mathrm{Co}-\mathrm{K} \alpha$ radiation produced by a rotating anode with voltage of $35 \mathrm{kV}$ and a current of $40 \mathrm{~mA}$ was used. The measurements were performed by continuous scanning modus with a detector window of $5^{\circ}$. The scanned range was from $42^{\circ}$ to $145^{\circ}$ in $2 \theta$ with a scan speed of $0.1^{\circ}$ per second. The evaluation of the data was performed using the Rietveld Method (Topas 4.2, Bruker-AXS) using a fundamental parameter approach after instrument description by measuring $\mathrm{LaB}_{6}$ reference.

Standard residual stress analysis. The investigation of residual stresses by the $\sin ^{2} \Psi$ method was done using a diffractometer of type MZ VI E (GE Inspection technology) with a PSD detector. The measurements were performed in martensite/bainite $\{211\}$ and RA $\{220\}$ phase using Cr- $\mathrm{K}_{\alpha}$ radiations and vanadium $\mathrm{K}_{\beta}$ filter. The $\mathrm{Cr}$-radiation was produced using a sealed tube operated at $33 \mathrm{kV}$ and $40 \mathrm{~mA}$ and a collimator with $2 \mathrm{~mm}$ diameter was used. The measurements were performed in a Chi-mode with tilt angles between $-45^{\circ}$ to $+45^{\circ}$ in 11 steps. For $\{211\}$, scan range was from $140^{\circ}$ to $164^{\circ}$ in $2 \theta$ with a scan speed of $0.006^{\circ}$ per second. For $\{220\}$, the scan range was from $125^{\circ}$ to $133^{\circ}$ in $2 \theta$ with a scan speed of $0.017^{\circ}$ per second. The peak position was determined by average gravity method after smoothing and linear background correction. The Young's modulus and Poisson coefficient used were $220 \mathrm{GPa}$ and 0.28 for $\alpha\{211\}$ and $207 \mathrm{GPa}$ and 0.28 for $\gamma\{220\}$ [7]. In order to establish the depth profiles for RA and RS, X-ray measurements were conducted at different pre-selected depth after electro-polishing. The electro-polishing was carried using an electrolyte solution containing $80 \% \mathrm{H}_{3} \mathrm{PO}_{4}$ and $20 \% \mathrm{H}_{2} \mathrm{SO}_{4}$. Correction of layer removal was performed at each depth according to Moore and Evans [8].

Evaluation of triaxial stresses. The evaluation of residual stress measurements using the standard $\sin ^{2} \psi$ method is based on the assumption that a plane stress state with the normal component equal to zero $\left(\sigma_{33}=0\right)$ is present due to low penetration depth of $\mathrm{Cr}-\mathrm{K} \alpha$ radiation $(\approx$ $5 \mu \mathrm{m})$. In a two-phase or multiphase material, $\sigma_{33}$ as well as $\sigma_{13}$ and $\sigma_{23}$ can exist in the different phases as pseudo-macrostress $\left(R S 2^{\text {nd }} K i n d\right)$. However, the evaluation of the $\sigma_{33}$ component requires the precise knowledge of $\mathrm{d}_{0}$ at each depth. In this work, (Eq. 1) was used to evaluate the $\sigma_{33}$ in the individual phases (retained austenite and martensite) [6]. The stressed lattice spacing $\left(d_{+}^{k}\right)$ of austenite and martensite was determined at each depth by individual peak $\gamma\{220\}$ and $\alpha\{211\} /\{112\}$ refinement of diffraction patterns using the Rietveld Method (TOPAS).

$$
\sigma_{33}^{k}=\frac{1}{\left(3 s_{1}^{k}+1 / 2^{s_{2}^{k}}\right)} \times\left[\left(\frac{d_{+}^{k}-d_{0}^{k}}{d_{0}^{k}}\right)-2 s_{1}^{k}\left(\sigma_{11}^{k}-\sigma_{33}^{k}\right)\right]
$$

$k$ refers to the austenite or martensite phase, $s_{1}$ and ${ }_{1 / 2} s_{2}$ are the X-ray Elastic Constants dependent on the interference plane and material phase, $d_{+}$and $d_{0}$ refers to the stressed and stressfree lattice spacing, $\sigma_{11}^{k}-\sigma_{33}^{k}$ corresponds to the value obtained using the standard $\sin ^{2} \psi$ method. With some adjustments of the factors in order to take into account that nitrogen and carbon is in solid solution, the stress-free lattice spacing $\mathrm{d}_{0}$ can be estimated by taking into account the dependence of martensite and austenite phase lattice parameters on carbon and nitrogen content in carbonitrided specimens as given in [9]. Such procedure has already been used in [10]. For austenite the equation $a_{0}=0.3573+0.00775 \times X_{C+N}$ was used and for martensite: $a_{0}=0.28664-0.0025 \times X_{C+N}$; $c_{0}=0.28664+0.00258 \times X_{C+N}$ where $X_{C+N}$ is the combined atomic percent of carbon and nitrogen in solid solution was used. The evaluation of the different stress components was done using following equations:

$$
\begin{aligned}
& \sigma_{11}^{\mathrm{k}}=\sigma_{22}^{\mathrm{k}}=\left(\sigma_{11}^{\mathrm{k}}-\sigma_{33}^{\mathrm{k}}\right)+\sigma_{33}^{\mathrm{k}} \\
& \sigma_{11}^{\text {macro }}=\sigma_{22}^{\text {macro }}=\sum\left(\sigma_{11}^{\mathrm{k}} \times \mathrm{X}^{\mathrm{k}}\right)
\end{aligned}
$$




$$
\sigma_{33}^{\operatorname{macro}}=\sum\left(\sigma_{33}^{\mathrm{k}} \times \mathrm{X}^{\mathrm{k}}\right)=0
$$

$\mathrm{X}^{\mathrm{k}}$ is the fraction of the considered phase. In order to evaluate the $\sigma_{33}$ component, two different strategies were used. First: Martensite and $R A$ phase contain equal amount of $C+N$ in solution equals to that of austenite before quenching. In this case, the $\mathrm{C}+\mathrm{N}$ content in solid solution in the phases was estimated by setting a condition satisfying the boundary condition $\sigma_{33}^{\text {macro }}=0$. The second strategy is: Martensite and $R A$ phase contain different amount of $C+N$ in solution. The difference in $\mathrm{C}+\mathrm{N}$ in solution can occur due to autotempering effects during which $\mathrm{RA}$ can be enriched and martensite can be depleted of $\mathrm{C}+\mathrm{N}$ in solution [11]. In this case, the relation $c / a=1+0.0099^{*} X_{C+N}$ for martensite given in [9] was used to estimate the $\mathrm{C}+\mathrm{N}$ in solid solution in martensite phase which was then fixed, whereas the $\mathrm{C}+\mathrm{N}$ content in solution in RA phase was estimated by setting the condition satisfying the boundary condition $\sigma_{33}^{\text {macro }}=0$.

\section{Results and discussion}

Initial results. The carbon and nitrogen depth profiles of the as-quenched specimens for both $\mathrm{CN} 1$ and $\mathrm{CN} 2$ conditions are shown in Fig. 1. The maximum concentration at a depth of $50 \mu \mathrm{m}$ was 0.56 Mass.- $\%$ C and 0.4 Mass.- $\% \mathrm{~N}$ for $\mathrm{CN} 1$ and 0.87 Mass.- $\% \mathrm{C}$ and 0.34 Mass.- $\% \mathrm{~N}$ for CN2. Moreover, in all specimens a depletion of alloying elements in the first $50 \mu \mathrm{m}$ of the case hardened layer which is associated to inter- and/or intra-granular oxidation and precipitates formation was observed by GDOES measurements. The depletion of alloying in this range may lead to bainitic transformation during quenching thereby reducing not only the hardness but also the level of compressive RS [12].

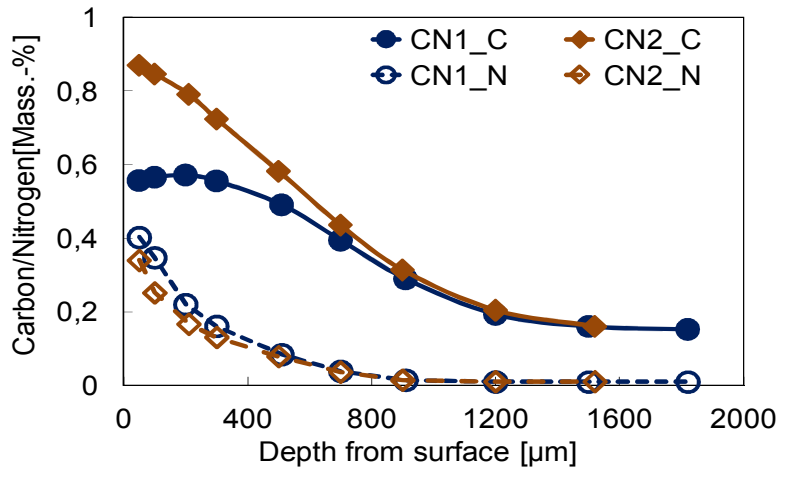

Fig. 1 Carbon and nitrogen depth profiles for both carbonitrided specimens (CN1, CN2) determined by SOES.

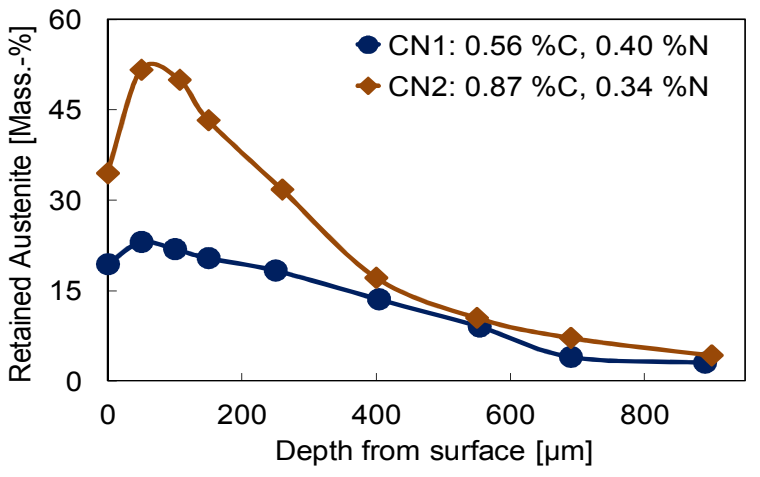

Fig. 2 Retained austenite depth profiles for both carbonitriding treatments (CN1, CN2) determined by XRD.

The retained austenite depth profiles determined by XRD after successive layer removal by electro-polishing are presented in Fig. 2. A maximum of about 23 and 51 Mass- $\%$ austenite at a depth of $50 \mu \mathrm{m}$ was retained for $\mathrm{CN} 1$ and $\mathrm{CN} 2$ specimens respectively. In all cases, the highest amount of retained austenite occurred at a depth around $50 \mu \mathrm{m}$ from the surface. Both specimens contain low value of RA in the first $50 \mu \mathrm{m}$ which is attributed to subsurface oxidation and depletion of alloying elements. Beyond $50 \mu \mathrm{m}$, the decrease of retained austenite correlates well with the carbon and nitrogen depth profiles in Fig. 1. The high amount of retained austenite in this range is mainly associated to the stabilization effect of carbon and nitrogen, quenching rate, quenchant temperature as well as thermal stresses which increase the energy necessary as a driving force for martensitic transformation [13].

Evaluation of residual stresses using the standard $\sin ^{2} \psi$ method. In the first instance, the measurements of the principal stresses in martensite and retained austenite according to the $\sin ^{2} \psi$ method are given in terms of $\sigma_{11}-\sigma_{33}$. The RS depth distribution in martensite and retained austenite for $\mathrm{CN} 1$ and $\mathrm{CN} 2$ are given in Fig. 3. As seen from the figure, at all points the martensite phase is in higher compression in comparison to the retained austenite. The maximum compressive residual stress in the martensite phase is about $-485 \mathrm{MPa}$ at a depth of $550 \mu \mathrm{m}$ for CN1 (Fig. 3a) and $-439 \mathrm{MPa}$ at a depth of $690 \mu \mathrm{m}$ for CN2 (Fig. 3b). These values are in the same range as the 
maximum compressive RS observed in [1] obtained after a survey of a number of carburized parts. Furthermore, both samples experienced less compressive residual stresses in the range of 50 to $400 \mu \mathrm{m}$ which can be explained by the high amount of RA. In this range, it can be observed that higher compressive RS are present in the specimen CN1 with less RA (Fig. 3a) than in the specimen CN2 with high RA (Fig. 3b). Though it is to be expected that retained austenite in the case-hardness layer may be set in compressive residual stress due to phase transformation in the core and martensitic transformation in the case, yet the co-existence of high RA amount in the case minimizes the magnitude of compressive stresses in both martensite and RA phase as well as shifting the location of maximum compressive RS toward the case/core interface. In both conditions, the location of maximum compressive residual stress occurs in the range of 40 to $60 \%$ of the total case depth $(\approx 1500 \mu \mathrm{m})$ where the proportion of martensite to austenite is about $80 \%$. At this depth, the amount of $\mathrm{C}+\mathrm{N}$ is about 0.5 Mass.- $\%$. At depths between 400 and $600 \mu \mathrm{m}$, the amount of RA in both treatments are almost similar. However, the measured residual stresses are different. This can be attributed to the differences in $\mathrm{C}+\mathrm{N}$ content in these layers (Fig 1) but also to the fact that the RS in these depths are influenced by the different RS in the upper layers (0 to 400 $\mu \mathrm{m}$ ). At depth above $600 \mu \mathrm{m}$, almost identical $\mathrm{C}+\mathrm{N}$ and RA profiles are obtained in both treatments and similar RS are present in martensite which both follow a comparable decrease.In the first 700 $\mu \mathrm{m}(\mathrm{RA}>10 \%)$, the macroscopic stresses are strongly influenced by the residual stresses present in austenite. Shifts of up to $60 \mathrm{MPa}$ compared to the residual stresses in martensite are reached. Beyond $700 \mu \mathrm{m}$ (RA $<10 \%$ ), the macroscopic stresses are assumed to correspond to that in martensite phase.
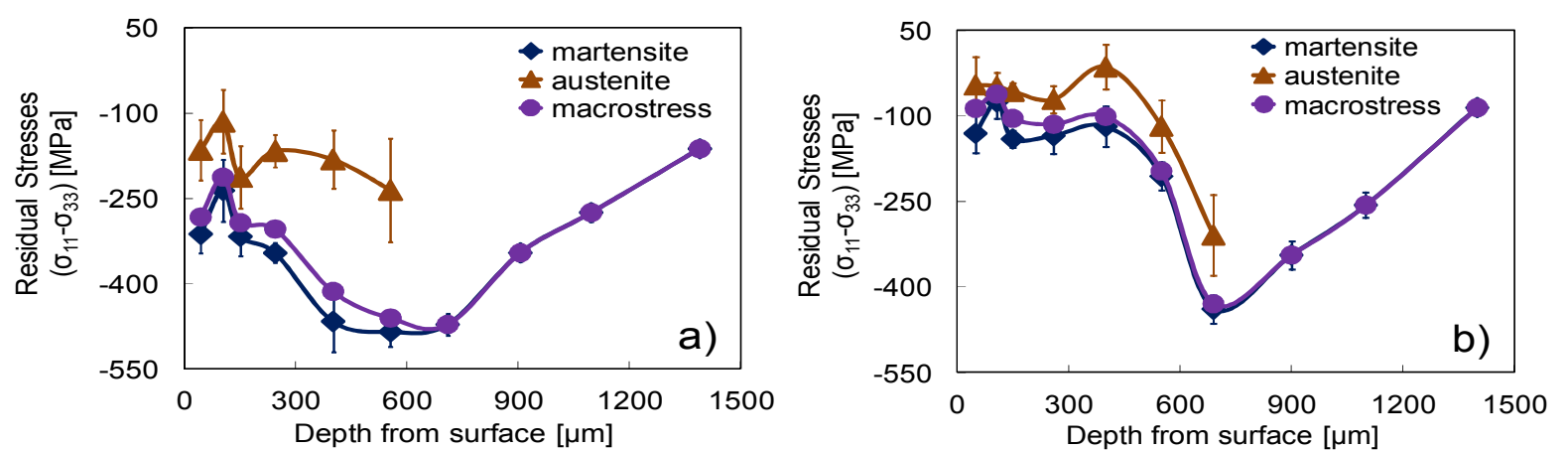

Fig. 3 Residual stress depth profiles obtained with the standard $\sin ^{2} \psi$ method with $\sigma_{33}=0: a$ ) specimen with $0.56 \% \mathrm{C}, 0.4 \% \mathrm{~N}$ (CN1); b) specimen with $0.87 \% \mathrm{C}, 0.34 \% \mathrm{~N}(\mathrm{CN} 2)$.

Stressed and stress-free lattice spacings for the treatment CN2. The determination of triaxial stresses in retained austenite and martensite requires the precise knowledge of the stress-free lattice spacing at each depth which in turn is strongly influenced by the amount of carbon and nitrogen in solid solution. The carbon and nitrogen in solid solution in the phases were estimated as explained in section "evaluation of triaxial residual stresses" for the treatment CN2. Fig. 4 shows the estimated carbon + nitrogen content in solid solution in martensite and retained austenite as a function of depth for the two considered evaluation strategies. The determined $\mathrm{C}+\mathrm{N}$ profile calculated with the first strategy considering equal $\mathrm{C}+\mathrm{N}$ content in martensite and retained austenite is close to the profile measured using OES. In consideration of the second strategy (i.e. Martensite and $R A$ phase contain different amount of $C+N$ in solution) the amount of $\mathrm{C}+\mathrm{N}$ in solid solution in $\mathrm{RA}$ is close to the OES values while the the $\mathrm{C}+\mathrm{N}$ content in martensite is about $0.2 \mathrm{Mass}-\%$ lower, what could be attributed to self-tempering effects as already observed in the literature [11].

Fig. 5 presents the corresponding variation of calculated $\mathrm{d}_{0}$ by taking into account the previously presented $\mathrm{C}+\mathrm{N}$ profile together with the experimentally determined lattice spacings as a function of the depth. The stressed lattice spacing for RA (Fig. 5a) is considerably smaller in comparison to the two stress-free lattice spacings data sets; consequently retained austenite phase will be set in compression state. By contrast, the measured lattice spacing for martensite phase at each depth is larger (Fig. 5b) than the two stress-free lattices spacing data sets; as a result martensite phase will be set in tension state. 


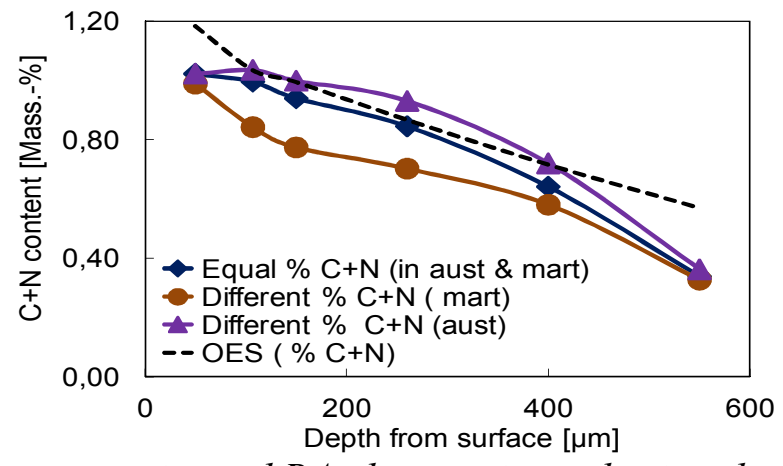

Fig. $4 C+N$ depth profiles in martensite and RA phase estimated using the boundary condition $\sigma_{33}^{\text {macro }}=0$ considering the two conditions for CN2.
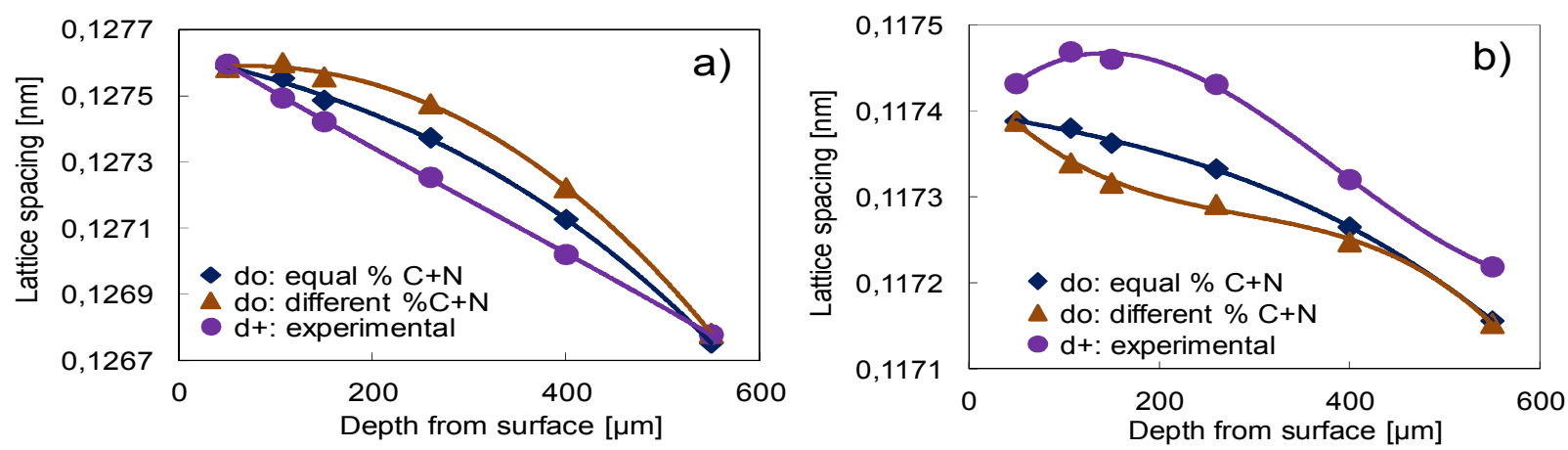

Fig. 5 Variation of calculated and experimentally determined lattice spacing for CN2: a) retained austenite $\{220\}$; b) martensite $\{211\}$

Triaxial residual stresses for the treatment CN2. Fig. 6 shows the calculated residual stress depth profiles. In consideration of the first strategy (equal $\% C+N$ in both $R A$ and martensite phase), it can be seen that although the magnitude of $\sigma_{11}$ and $\sigma_{33}$ in both phases are slightly different, they exhibit similar distributions trends. Both RA and martensite phase experienced minimum residual stresses $(\approx 0 \mathrm{MPa})$ at a depth of $50 \mu \mathrm{m}$. This can be explained by the high amount of retained austenite of about 51 Mass.-\% (Fig. 2). In RA (Fig. 6a), the RS rise through compressive and reaches maximum close to $-600 \mathrm{MPa}$ at a depth of about $260 \mu \mathrm{m}$ for $\sigma_{11}$ and $-530 \mathrm{MPa}$ for $\sigma_{33}$. With increasing depth, the high compressive residual stresses decrease continuously. In martensite (Fig. 6b), the RS rise through tension and reach maximum nearby $200 \mathrm{MPa}$ for $\sigma_{11}$ and $280 \mathrm{MPa}$ for $\sigma_{33}$ both occurring at a depth of $100 \mu \mathrm{m}$. With increasing depth, both residual stress components decrease progressively and reach values close to 0 at $550 \mu \mathrm{m}$.
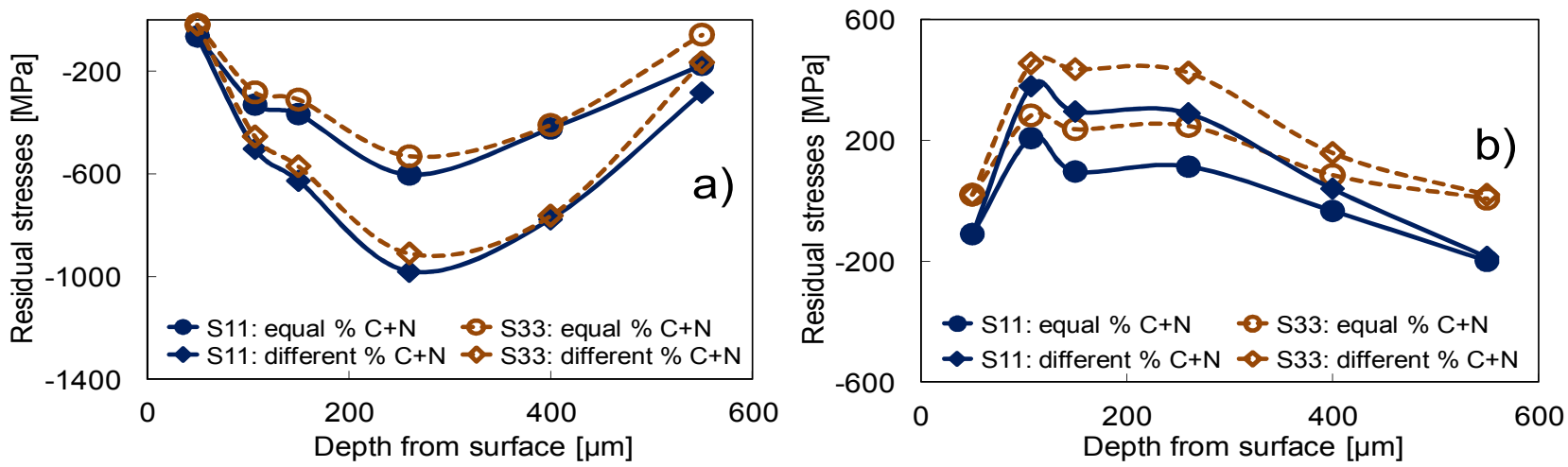

Fig. 6 Calculated triaxial residual stresses for specimen (CN2) a) retained austenite b) martensite. Assumptions: 1 - martensite and $R A$ contain equal $\% C+N$ in solution; 2 - martensite and $R A$ contain different $\% C+N$ in solution.

In consideration of the second strategy, similar trend of residual stress distribution with high maximum residual stresses can be observed. In this case, the maximum compressive RS determined for RA is $-980 \mathrm{MPa}$ for $\sigma_{11}$ and $-900 \mathrm{MPa}$ for $\sigma_{33}$ both at a depth of about $260 \mu \mathrm{m}$. For martensite, maximum tensile stresses of $380 \mathrm{MPa}$ for $\sigma_{11}$ and $450 \mathrm{MPa}$ for $\sigma_{33}$ occur at a depth of $100 \mu \mathrm{m}$. The 
high magnitude of $\sigma_{33}$ in the second strategy is associated to higher carbon/nitrogen values in RA and depletion in martensite [11]. The enrichment in RA leads to the increase in the stress-free lattice spacing which is why higher magnitudes of compressive RS were determined. On the other hand, the depletion in martensite leads to the decrease in the stress-free lattice spacing and therefore, high magnitudes of tensile RS are resulting.

Generally, the standard $\sin ^{2} \psi$ method utilizes the assumption of $\sigma_{33 \text { (pseudo, macro) }}=0$ for the evaluation of RS in a monophase or multiphase material. The two strategies considered indicate however, the presence of high magnitude of $\sigma_{33}$ of opposite signs in each phase. This in turn confirms that pseudo-macrostress $\sigma_{33}$ should be considered during evaluation of RS in a multiphase material. However, under these two strategies there was no difference in macroscopic stresses $\left(\sigma_{1 \text { macro }}\right)$ as the boundary condition $\sigma_{33 \text { macro }}=0$ was used and the values were identical to the ones determined using the standard $\sin ^{2} \psi$ method given in Fig. 3. If $\sigma_{33 \text { macro }}$ is non-zero, differences in the macroscopic $\sigma_{11}$ values could result.

\section{Summary}

In this work, residual stress depth profiles evaluated using the standard $\sin ^{2} \psi$ method are presented. The $\mathrm{C}+\mathrm{N}$ content in solution highly influences the sign, magnitude and the distribution of RS. Low compressive residual stresses occur in the subsurface where the proportion of martensite to austenite is low while the maximum compressive RS occur at 40 to $60 \%$ of the case depth where the proportion of martensite to austenite is high. Differences were measured between the RS in RA and martensite, so that macroscopic RS values were influenced. From these investigations, it appears that when the fraction of retained austenite is greater than $15 \%$, it is important to measure the RS in both phases in order to determine the macroscopic RS by considering the proportion of each phase.

In addition, different methods for evaluation of triaxial RS were presented. High compressive triaxial RS in RA and high tensile RS in martensite phase were observed, what confirms that even within the low penetration depth of Cr-ka radiation, non-zero $\sigma_{33}$ components are present in both phases. The magnitude of RS in both phases is highly dependent on $\mathrm{C}+\mathrm{N}$ in solid solution at each depth.

\section{References}

[1] J.R. Davis, SURFACE HARDENING OF STEEL - Understanding the Basic, ASM International, 2002.

[2] T. Réti, Handbook of Residual Stress and Deformation of Steel, ASM International, 2002, p. 189-208.

[3] S. Bischoff, H. Klümper-Westkamp, F. Hoffmann, H. W. Zoch, HTM J. Heat Treatm. Mat. 65 (2010) 3, pp. 141-148.

[4] A. Zumbilev, H. Panayotov and I. Zumbilev, Annals of Faculty of Engineering Hunedoara International Journal of Engineering, Tome IX (2011), Fascicule 2, (ISSN 1584-2665).

[5] C. Kim, D.E. Diesburg and R.M. Buck: J. Heat Treat. Vol. 2 (No. 1), June 1981, p 43-53.

[6] V. Hauk, Structural and Residual Stress Analysis by Nondestructive Methods, Elsevier, Amsterdam, 1997.

[7] B. Eigenmann, E. Macherauch, Mat.-wiss.u. Werkstofftech. 27, 426-437 (1996)

[8] G. Totten, M. Howes, T. Inoue (Eds), Handbook of Residual Stress and Deformation of Steel, ASM International, 2002.

[9] L. Cheng, A. Böttger, Th. H. de Keijser, E.J. Mittemeijer, Scripta Metallurgica \& Materialia, Vol. 24, 1990, pp. 509-514.

[10] J. Epp, T. Hirsch, M. Hunkel, R. Wimpory, Materials Science Forum, 652 (2010), S 37-43.

[11] J. Epp, T. Hirsch, C. Curfs, Metallurgical and Materials Transactions A, Vol. 43A, (2012) p. 2210-2217.

[12] G. Parrish, Carburizing: Microstructures and Properties, ASM International, 1999.

[13] A. Kokosza, J. Pacyna, Journal of Materials Processing Technology, 162-163 (2005) 327-331. 